Jurnal Syntax Imperatif : Jurnal Ilmu Sosial dan

Pendidikan

p-ISSN: 2721-2491e-ISSN : 2721-2246

Vol. 1, No. 1, Maret 2020

\title{
PELAKSANAAN KURIKULUM TERPADU DI SEKOLAH DASAR ISLAM TERPADU (SDIT) IBNU TAIMIYAH SUKAJADI BANDUNG
}

\section{Hoiruddin Fathurohman}

Program Studi Pendidikan Agama Islam, Sekolah Tinggi Agama Islam (STAI) Persis

Bandung, Indonesia

Email : khoerudinibnada@gmail.com

\begin{abstract}
Abstrak
Kurikulum merupakan komponen dan pegangan pokok yang harus menjadi acuan dalam pelaksanaan pendidikan, kurikulum menjadi alat ukur untuk meningkatkan kualitas mutu satuan pendidikan tertentu. Salah satu kurikulum yang dikembangkan adalah kurikulum terpadu, yaitu memadukan beberapa jenis kurikulum yang dilaksanakan dalam satu jenjang pendidikan. Diantara perpaduan jenis kurikulum yaitu perpaduan antara kurikulum dari Dinas Pendidikan Nasionaldengan kurikulum satuan pendidikan. Penelitian ini bertujuan untuk mengetahui proses pelaksanaan kurikulum terpadu di Sekolah Dasar Islam Terpadu (SDIT) Ibnu Taimiyah Sukajadi Bandung serta faktor pendukung dan penghambat proses pelaksanaan kurikulum terpadu SDIT Ibnu Taimiyah Sukajadi Bandung. Penelitian ini menggunakan metode deskriftif kualitatif, hasil penelitian menunjukan bahwa: 1) SDIT Ibnu Taimiyah memadukan 3 kurikulum yaitu kurikulum dari Diknas, kurikulum sekolah, dan kurikulum yayasan. 2) pelaksanaan kurikulum terpadu SDIT Ibnu Taimiyah mengacu kepada kurikulum tematik diknas yang kemudian diintegrasikan dengan kurikulum sekolah dan yayasan yaitu memadukan nilai-nilai islam dan pendidikan karakter di dalamnya. SDIT Ibnu Taimiyah telah melaksanakan pembelajaran dengan model kurikulum terpadu dengan baik, hal ini dapat dilihat dari kepercayaan masyarakat karena lulusan dari SDIT Ibnu Taimiyah sudah memiliki standar kompetensi yang baik.
\end{abstract}

\section{Pendahuluan}

Pendidikan adalah usaha sadar dan terencana untuk mewujudkan suasana belajar dan proses pembelajaran agar peserta didik secara aktif mengembangkan potensi dirinya untuk memiliki kekuatan spiritual keagamaan, pengendalian diri, kepribadian, kecerdasan, akhlak mulia, serta keterampilan yang diperlukan dirinya, masyarakat, bangsa dan negara (Nomor, 20AD).

Untuk itu pendidikan merupakan kunci utama untuk mempersiapkan generasi muda masa depan. Pendidikan mempunyai peranan besar dalam membentuk manusia yang berkualitas yang mampu hidup dengan baik di masyarakat nantinya.

Dalam mencapai hal itu maka pendidikan yang dilakukan haruslah pendidikan yang mempunyai kualitas dan mutu pendidikan yang baik. Upaya peningkatan kualitas pendidikan terus menerus dilakukan baik secara konvensional maupun inovatif. Hal tersebut sesuai dengan amanat tujuan sistem pendidikan nasional adalah untuk meningkatkan mutu pendidikan pada setiap jenis dan jenjang pendidikan.

Upaya peningkatan mutu pendidikan dilakukan dari semua komponen pendidikan mulai dari tujuan, isi, dan pedoman penyelenggaraan pendidikan. Komponen-komponen itu dimuat dan diimplementasikan menjadi sebuah Kurikulumpendidikan. Upaya untuk 
meningkatkan kualitas pendidikan adalah dengan meningkatkan kualitas kurikulum pendidikan dengan cara pengembangan kurikulum.

Keberhasilan suatu kurikulum merupakan proses panjang, mulai dari kristalisasi berbagai gagasan dan konsep ideal tentang pendidikan, perumusan desain kurikulum, persiapan pendidik dan tenaga kependidikan, serta sarana dan prasarana, tata kelola pelaksanaan kurikulum -termasuk pembelajaran-- dan penilaian pembelajaran. Struktur kurikulum dalam hal perumusan desain kurikulum, menjadi amat penting. Kurikulum harus sesuai dengan karakteristik siswa dan sekolah.

Kurikulum secara etimologi berasal dari bahasa Latin Curriculum, yang semula berarti a running course, a specially a chariot race course, dan terdapat pula dalam bahasa Perancis "Courier" yang berarti "to run" (berlari). Dalam mendefinisikan kurikulum, para ahli saling berbeda pendapat. Dalam pandangan klasik, kurikulum lebih ditekankan sebagai rencana pelajaran di suatu sekolah. Adapun dalam pandangan modern, kurikulum lebih dianggap sebagai suatu pengalaman atau sesuatu yang nyata terjadi dalam proses pendidikan (Fitri, 2013)

Kurikulum Pendidikan Islam diartikan sebagai rancangan pendidikan dan pembelajaran yang berisi learning program (program pembelajaran), learning experoence (pengalaman belajar), dan planedlearning program (perencanaan program pembelajaran) pendidikan Islam yang akan diberikan kepada peserta didik agar dapat menjadi pribadi yang beriman dan bertaqwa kepada Allah Swt. memiliki keterampilan hidup yang dijiwai oleh ajaran Islam dan nilai Islam yang bersumber dari al-Quran dan as-Sunnah sehingga menjadi pribadi yang paripurna (kamil) (Fitri, 2013)

\section{Metode Penelitian}

Dalam mencapai sebuah tujuan pasti menempuhnya melakukan berbagai cara atau metode. Metode penelitian yang digunakan dalam penelitian ini adalah metode deskriftif kualitatif. Karena penelitian ini merupakan penelitian yang terikat dengan nilai-nilai yang dibawa sumber data dan menggali tentang penerapan sebuah konsep yaitu pelaksanaan kurikulum terpadu SDIT Ibnu Taimiyah.

\section{Hasil dan Pembahasan}

Pengertian kurikulum menurut Undang-undang sistem pendidikan nasional adalah seperangkat rencana dan pengaturan mengenai tujuan, isi, dan bahan pelajaran serta cara yang digunakan sebagai pedoman penyelenggaraan kegiatan pembelajaran untuk mencapai tujuan pendidikan tertentu (Nasional, 2003) Kurikulum juga merupakan suatu rencana pendidikan, memberikan pedoman dan pegangan tentang jenis, lingkup dan urutan isi, serta proses pendidikan (Syaodih Sukmadinata, 2007)

Sekolah Islam Terpadu (SIT) muncul mencoba membangun pendidikan yang berkualitas. salah satunya dengan berupaya menciptakan pengajaran yang seimbang antara ilmu pengetahuan dengan nilai-nilai Islam di dalamnya, dengan mengintegrasikan berbagai komponen kegiatan keislaman yang mampu membentuk pendidikan berkarakter yang kokoh dan efektif (Robingatin, 2015). Hal itu sesuai 
dengan kurikulum Sekolah Islam Terpadu yang dinamakan Kurikulum Terpadu (terintegrasi).

Kemunculan beberapa Sekolah Islam terpadu dimaksudkan untuk meningkatkan kualitas pendidikan serta menjawab keresahan masyarakat Indonesia yang mayoritas beragama Islam yang menginginkan adanya sebuah institusi pendidikan Islam yang berkomitmen mengamalkan nilai-nilai islam dalam sistemnya, dan bertujuan agar siswanya mempunyai kompetensi seimbang antara ilmu kauniyah dengan ilmu qauliyah, antara fikriyah, ruhiyyah dan jasadiyyah, sehingga mampu melahirkan generasi muda muslim yang berilmu, berwawasan luas dan bermanfaat bagi ummat.

Dengan tujuan menciptakan siswa yang memiliki kecerdasan Intelektual Fenomena munculnya sekolah Islam Terpadu (SIT) yang akhir-akhir ini disponsori oleh Jaringan Sekolah Islam Terpadu (JSIT). Keberanian menggunakan label agama dalam penyelenggaran pendidikan ternyata mendapat tempat tersendiri di hati masyarakat. Keunggulan SIT diantaranya adalah memiliki keterpaduan aspek moralitas dan intelektualitas yang ditanamkan kepada siswa dengan dukungan seluruh sivitas akademika yang ada di lingkungan sekolah.

Masyarakat yang sudah merasa khawatir terhadap keselamatan putra-putrinya meyakini bahwa dengan menyekolahkan anaknya pada sekolah yang berbasis agama merupakan upaya preventif untuk melindungi generasi bangsa dari ancaman penyakit masyarakat, terlebih pada pendidikan dasar yang merupakan aspek fundamental dari pendidikan yang lain (Kadi, 2015).

Sekolah Dasar Islam Terpadu (SDIT) IbnuTaimiyah merupakan salah satu Sekolah Islam Terpadu tingkat dasar yang berada di kota Bandung yang menerapkan kurikulum terpadu. Hal ini dapat terlihat dari pengamatan sementara bahwa dalam proses belajar mengajar yang dilaksanakan oleh SDIT Ibnu Taimiyah yang memadukan Pendidikan Agama Islam dan di Sekolah Dasar Islam Terpadu (SDIT) Ibnu Taimiyah Sukajadi Bandung.

\section{Perencanaan Kurikulum}

Kurikulum terpadu SDIT Ibnu Taimiyah dirancang sesuai dengan tujuan sekolah, yaitu mewujudkan generasi Islam yang berakhlakul karimah. Dan dapat dipahami bahwa kurikulum SDIT Ibnu Taimiyah ialah dengan mengintegrasikan kurikulum nasional yang tematik dengan nilai-nilai agama. Jadi kurikulum terpadu SDIT Ibnu Taimiyah ialah perpaduan antara ilmu-ilmu umum dengan Pendidikan Agama Islam. Nilai-nilai agama diintegrasikan dalam semua pelajaran ini artinya ketika guru menyampaikan sebuah mata pelajaran kepada siswa guru menintegrasikan pelajaran yang disampaikannya itu dengan agama. Kemudian di dalam buku pedoman Parent Handbook SDIT Ibnu Taimiyah juga dijelaskan.

Kurikulum yang dilaksanakan di SDIT Ibnu Taimiyah ialah kurikulum dari Dinas yaitu kurikulum 2013. SDIT Ibnu Taimiyah sama sekali tidak mengurangi mata pelajaran yang ada di kurikulum 2013 sehingga Kompetensi Dasar tetap tersampaikan kepada siswa, hanya saja SDIT Ibnu Taimiyah mempunyai kurikulum tersendiri untuk 
agama dan kurikulum itu diintegrasikan dengan semua mata pelajaran yang ada di kurikulum Dinas, dan yang menjadi keterpaduan di dalam kurikulum SDIT Ibnu Taimiyah itu setiap mata pelajaran apapun selalu dikaitkan dengan agama.

Kurikulum terpadu SDIT Ibnu Taimiyah dinamakan dengan Kurikulum SDIT Ibnu Taimiyah, karena kurikulum SDIT Ibnu Taimiyah adalah perpaduan antara Kurikulum 2013 dengan kurikulum sekolah, ditambah juga dengan kurikulum dari yayasan yaitu pendidikan karakter.

Kurikulum terpadu yang dipakai di SDIT Ibnu Taimiyah memadukan kurikulum nasional dengan kurikulum kekhasan Islam terpadu yang dimiliki sekolahan tersebut. Kurikulum yang menekankan pada nilai-nilai Islami yang dikolaborasikan dengan pelajaran umum menjadikan pembelajaran bernuansa Islami. Peserta didik selain mendapat pelajaran umum juga mendapatkan penerapan nilai-nilai Islami yang bisa diimplementasikan dalam kehidupan sehari-hari. Guru yang mengajarkan materi di kelas memberikan sisipan nilai-nilai islami yang disesuaikan dengan Al-Qur'an dan hadis. Apapun materi yang disampaikan guru dikaitkan dengan ayat-ayat Al-Qur'an atau hadis yang kemudian dijabarkan sesuai materi yang diajarkan. Peserta didik selain belajar juga mendapat pemahaman pentingnya nilai-nilai Islami di setiap pelajaran.

Proses perencanaan yang dilaksanakan oleh SDIT Ibnu Taimiyah itu sama dengan sekolah lain yaitu dengan menyusun silabus dan RPP, hanya saja pada perencanaan tersebut silabus dan RPP yang digunakan dari Diknas dan kemudian diintegrasikan dengan kurikulum SDIT Ibnu Taimiyah. Kembali Wakasek Kurikulum SDIT Ibnu Taimiyah menjelaskan: "Sebetulnya perencanaan nya sama saja kita menyusun silabus dan RPP yang dari Diknas, kemudian kita singkronkan KD nya dengan nilai-nilai agama."

SDIT Ibnu Taimiyah tidak menggunakan buku penerbit untuk proses pembelajaran siswa, buku penerbit hanya menjadi referensi bagi guru untuk membuat LKS. Setiap guru merancang proses pembelajaran yang akan dilaksanakannya dengan membuat LKS oleh masing-masing, hal ini dilakukan karena pada dasarnya seorang guru akan lebih mengetahui dan paham terhadap siswa, maka SDIT Ibnu Taimiyah memberikan keluasan kepada guru untuk membuat LKS yang sesuai dengan kebutuhan siswa.

Dalam proses perencanaan yang dilaksanakan SDIT Ibnu Taimiyah dirancang tema-tema dengan matang, namun kadang pula tema yang akan disampaikan dirancang secara spontan, misalkan tadi yang seharusnya pada bulan agustus itu menyampaikan tema tertentu yang sudah dirancang, kemudian kebijakan kurikulum harus menyampaikan tema yang berbeda. Ini adalah bentuk keterpaduannya dengan nilai-nilai agama. Namun pada prosesnya kompetensi dasar yang dari Diknas tetap tersampaikan, karena tema yang harusnya disampaikan bukan tidak jadi untuk disampaikan melainkan dirolling. Perencanaan kurikulum terpadu SDIT Ibnu Taimiyah adalah seperti berikut: Pertama: perencanaan kurikulum terpadu SDIT Ibnu Taimiyah dilaksanakan dua tahap, tahap pertama adalah ketika pada awal semester diadakan Rapat Kerja (Rapat Kerja) pada saat itu dilakukan perencanaan oleh semua guru SDIT Ibnu Taimiyah dengan 
pengawasan Wakasek Kurikulum SDIT Ibnu Taimiyah dan juga dari pihak yayasan, dirancang tema-tema yang akan disampaikan selama satu semester dan dikaitkan dengan nilai-nilai Pendidikan Agama Islam. Tahap kedua perencanaan dilakukan oleh masing-masing guru yang dituangkan dalam bentuk RPP dan LKS. Kedua: perencanaan yang dilakukan oleh SDIT Ibnu Taimiyah dirancang secara tematik dan dirancang dengan baik, namun ada kalanya dirancang berdasarkan spontan karena mengaitkan tema dengan kebutuhan siswa.

Dari hasil perencanaan bahwa kurikulum terpadu di SD Ibnu Taimiyah Pembelajaran yang diimplementasikan didukung dengan kurikulum khas sekolah Islam terpadu dengan dikaitkan ayat suci Al-Qur'an dan sunnah sehingga muatan kurikulum tidak hanya pengetahuan saja tetapi ada penguatan keislaman pada diri anak sehingga muncul generasi yang unggul dalam karakter.

\section{Pelaksanaan Kurikulum}

Proses pelaksanaan kurikulum terpadu SDIT Ibnu Taimiyah berdasarkan proses pelaksanaan pembelajaran, karena pembelajaran adalah merupakan komponen dari kurikulum. Waktu pelaksanaan pembelajaran SDIT Ibnu Taimiyah dari mulai hari senin - jum'at dan Full Day School. Dalam proses belajar mengajar di dalam kelas SDIT Ibnu Taimiyah melakukan Team Teaching yaitu di dalam kelas terdapat dua orang guru yang mengajar yaitu guru kelas dengan guru PAI.

Proses pembelajaran yang dilaksanakan SDIT Ibnu Taimiyah ialah dengan cara Team Teaching yaitu proses pembelajaran dilakukan oleh lebih dari satu orang, dan masing-masing guru saling membantu akan prosesnya pembelajaran. Disetiap tingkatan kelas mulai dari kelas satu sampai dengan enam proses pembelajaran dilaksanakan dengan dua orang guru, dan guru yang melaksanakan proses pembelajaran nya itu guru kelas dan guru PAI ini merupakan pengintegrasian antara ilmu umum dan agama yang dilaksanakan SDIT Ibnu taimiyah.

Semua kurikulum dipadukan secara seimbang dengan penguatan pembiasaan Islami seperti sholat dhuha, makan dengan duduk, menghormati guru, hafalan suratsurat pendek sebelum pelajaran, mengucapkan kalimat toyyibah, gemar berinfaq, dzikir pagi setiap jum'at, mengikuti pembinaan karakter peserta didik, dan sebagainya.

Selain proses pembelajaran di kelas SDIT Ibnu Taimiyah pun melaksanakan pembelajaran di luar kelas yaitu dinamakan dengan Field Trip. Field Trip SDIT Ibnu Taimiyah dilaksanakan setiap satu semester sekali dan dua objek wisata. Field Trip SDIT Ibnu Taimiyah bertujuan untuk agar siswa dapat menghindari rasa bosan belajar di kelas dan mengajak untuk refreshing sejenak dari kegiatan sekolah. Field trip tidak hanya sekedar bersenang-senang, tetapi juga ingin memberikan pelajaran dan pengalaman yang menyenangkan. Dan disaat Field Trip kembali guru PAI memiliki tugas untuk menyampaikan nilai-nilai agama yang berkaitan dengan apa yang siswa temukan.

Selain Field Trip SDIT Ibnu Taimiyah memiliki program Kepanduan yaitu Muatan lokal wajib bagi siswa proses pembelajaran di luar kelas meskipun materi itu 
mestinya disampiakan di kelas, guru menjadi fasilitator dan penyampian materi dengan tidak ceramah, dengan tujuan merefresh para siswa, metodenya seperti kemping, baris berbaris, simpul, dll. Dan program kepanduang adalah yang dinanti oleh para siswa.

SDIT Ibnu Taimiyah juga mempunyai kurikulum khusus mengenai pendidikan karakter bagi para siswa, dengan yayasan yang langsung menyampaikan pendidikan karakter untuk siswa nya. Dengan pendidikan karakter yang diberikan siswa mengatahui dan paham mengenai akhlaq kepada orang tua, kejujuran, kedisiplinan, tanggung jawab, bershodaqoh, kasih sayang, meminta maaf dan tolong, kebersihan, kerjasama, dan sabar. Pendidikan karakter ini memiliki waktu khusus bagi setiap kelas, yaitu dalam satu minggu satu kelas memiliki waktu pendidikan karakter satu hari selama 3x15 menit. Proses pelaksanaan kurikulum terpadu SDIT Ibnu Taimiyah adalah sebagai berikut: Pertama: waktu pelaksanaan proses kurikulum terpadu SDIT Ibnu Taimiyah adalah 5 hari dari hari senin sampai jum'at dan Full Day. Kedua: proses pembelajaran SDIT Ibnu Taimiyah dilaksanakan dengan Team Teaching yaitu di dalam satu kelas terdiri dari guru kelas dan guru PAI. Guru PAI bertugas untuk membantu guru kelas dalam mengaitkan nilai-nilai agama terhadap mata pelajaran umum dan membantu siswa yang mengalami kesulitan belajar. Ketiga: proses pembelajaran SDIT Ibnu Taimiyah tidak hanya dilaksanakan di kelas ada juga dilaksanakan di luar kelas dengan mengadakan kependauan dan Field Trip.

\section{Kesimpulan}

Perencanaan kurikulum terpadu Sekolah Dasar Islam Terpadu (SDIT) Ibnu Taimiyah Sukajadi Bandung memadukan kurikulum dinas dengan kurikulum SDIT Ibnu Taimiyah dengan penanaman nilai-nilai Islami. Kurikulum terpadu SD Ibnu Taimiyah Pembelajaran yang diimplementasikan didukung dengan kurikulum khas sekolah Islam terpadu dengan dikaitkan ayat suci Al-Qur'an dan sunnah sehingga muatan kurikulum tidak hanya pengetahuan saja tetapi ada penguatan keislaman pada diri anak sehingga muncul generasi yang unggul dalam karakter.Pelaksanaan model kurikulum terpadu SDIT Ibnu Taimiyahsudah berjalan baik. Pembelajaran telah dilakukan dengan cara Team Teaching guru kelas berkolaborasi dengan guru PAI dengan tujuan memadukan ilmu-ilmu umum dengan ilmu agama.

Faktor pendukung pelaksanaan kurikulum terpadu SDIT Ibnu Taimiyah adalah pimpinan sekolah dan yayasan SDIT Ibnu Taimiyah bekerja sama dengan baik dalam pelaksanaan pengembangan sekolah, sehingga tersedianya fasilitas sarana dan prasarana yang dibutuhkan sekolah untuk proses pelaksanaan dan pengembangan kurikulum terpadu di SDIT Ibnu Taimiyah. Sedangkan faktor penghambatnya adalah waktu yang tidak menentu untuk merencanakan kurikulum, sulit mengkoordinir anak berkebutuhan khusus. 


\section{BIBLIOGRAFI}

Abdullah Idi, Pengembangan Kurikulum Teori \& Praktek Jogjakarta: Ar-Ruzz Media, (2011)

Agus Zaenul Fitri, Manajemen Kurikulum Pendidikan Islam: dari Normatif-Filosofis ke Praktis, Bandung: Alfabeta, (2013)

Ahmad Tafsir, Ilmu Pendidikan Islam, Bandung: PT Remaja Rosdakarya, Cet. Ke-2 (2013)

Ansar Zainuddin. (2017). Konsep Pendidikan Sekolah Islam Terpadu. [online]: http://www.kumpulanmakalah.com/2016/10/konsep-pendidikan-sekolah-islamterpadu.html [30 Januari 2018].

Dakir, Perencanaan dan Pengembangan Kurikulum, (Jakarta: Rineka Cipta, 2004)

Endang Mulyasa, Kurikulum Tingkat Satuan Pendidikan, Suatu Panduan Praktis, Bandung: Remaja Rosdakarya, (2006)

Eveline Siregar dan Hartini Nara, Teori Belajar dan Pembelajaran, (Bogor: Ghalia Indonesia, Cet. Ke-2 (2011)

Khairuddin dan Mahfud Junaedi, Kurikulum Tingkat Satuan Pendidikan (KTSP), Semarang: MDC Madrasah Development Center, (2007)

Lexy J. Moleong, Metodologi Penelitian Kualitatif, Bandung: PT Remaja Rosdakarya, Cet. Ke-29 (2011)

Model Kurikulum Fullday School Dengan Sistem Terpadu Di Sekolah Dasar (Sd) Islam Terpadu Cordova Samarinda.

Nana Syaodih Sukmadinata, Pengembangan Kurikulum: Teori dan Praktik, Bandung: Rosdakarya, (2001)

Oemar Hamalik, Dasar-Dasar Pengembanagn Kurikulum, Bandung: Remaja Rosdakarya, (2007)

S. Nasution, Azas-azas Kurikulum, Jakarta: Bumi Aksara, (2003),

Siti Robingatin, Implementasi Kurikulum Jaringan Sekolah Islam Terpadu Di Sekolah Menengah Pertama Islam Terpadu. Syamil. Vol 3 No. 1, (2015)

Syaifuddin Sabda, Model Kurikulum, Yogyakarta: Pustaka. (1999)

Titi Kadi, Model Kurikulum Fullday School Dengan Sistem Terpadu Di Sekolah Dasar (SD) Islam Terpadu Cordova Samarinda. Syamil Vol 3 No. 1, 2015

Trianto, Model Pembelajaran Terpadu Konsep, Strategi, dan Implementasinya Dalam Kurikukulum Tingkat Satuan Pendidikan (KTSP), Jakarta: Bumi Aksara, (2010) 
Hoiruddin Fathurohman

Undang-Undang RI Nomor 20 Tahun 2003 Tentang Sistem Pendidikan Nasional Pasal 1 ayat 1

Undang-Undang RI Nomor 20 Tahun 2003 Tentang Sistem Pendidikan Nasional Pasal 1 ayat 19

Zainal Arifin, Pengembangan Manajemen Mutu Kurikulum Pendidikan Islam, Yogyakarta: Diva Press, (2012) 